\title{
OS BURACOS DA LOUSA: REFLEXÕES SOBRE UM TEMA DE PESQUISA
}

\author{
SILVIA ELIZABETH MORAES \\ Pesquisadora visitante da Universidade Federal do Ceará \\ silviamoraes@secrel.com.br
}

\begin{abstract}
RESUMO
Este artigo examina a validade, relevância e exeqüibilidade de um tema de Trabalho de Conclusão de Curso de Licenciatura em Pedagogia. Discute quais critérios podem ser utilizados pelos professores-orientadores no julgamento de um tema de pesquisa para analisar caminhos e resultados esperados em monografias, dissertações e teses em geral. Salienta o processo de construção de um saber teórico-prático tanto por parte do aluno quanto por parte do professor-orientador. Vale-se de um estudo de caso, recorrendo à coleta de dados feita através da análise documental, observação participante, entrevista gravada e conversas telefônicas. Conclui que na pesquisa em educação é necessário formular perguntas simples que tenham a capacidade de relacionar o micro com o macro, o individual com o coletivo, o tópico com o tema, a ciência com a vida.

PESQUISA EDUCACIONAL - ORIENTAÇÃO EDUCACIONAL - AVALIAÇÃODAAPRENDIZAGEM - ESTUDO DE CASO
\end{abstract}

\section{ABSTRACT}

THE HOLES IN THE CHALKBOARD: REFLECTIONS ON A RESEARCH TOPIC. This article analyses the validity, relevance and feasibility of an undergraduate research topic in Education. It starts with a question - which criteria can we, advisors, use in judging a good research theme - in order to analyze ways and results expected in graduate and post-graduate thesis and dissertations. It emphasizes the process of constructing a theoretical-practical knowledge as much as for the student and the teacher-advisor. A case study approach is adopted and the data were collected through documental analysis, participant observation, recorded interview and telephone conversations. The conclusion is that in educational research it is necessary to formulate simple questions that are capable of relating the micro with the macro, the individual with the collective, the topic with the theme, science with life. EDUCATIONAL RESEARCH-EDUCATIONAL GUIDANCE - LEARNING EVALUATION CASE STUDY

Com os agradecimentos a Marlene Banes. 
Meu caso é a Marlene. Nossa relação orientadora-orientanda transformou-se em algo mais do que nos era exigido pelo PEC', a ponto de converter sua passagem em minha vida profissional em um estudo de caso. Para ela, escrever um Trabalho de Conclusão de Curso - TCC - valeu como aprendizado dos primeiros passos no campo da pesquisa; para mim, orientá-la serviu de estímulo para me tornar melhor professora, orientadora e ser humano.

Da rica experiência de orientar Marlene, discuto, neste artigo, critérios de validade, relevância e exeqüibilidade que nós professores-orientadores utilizamos no julgamento de um tema de pesquisa. Partindo dessa questão, analiso caminhos e resultados esperados em monografias, dissertações e teses em geral. Tomo como pressuposto básico que as pesquisas educacionais devem necessariamente gerar um saber teórico-prático que integrará o conhecimento tanto do aluno quanto do professor-orientador e que este saber é construído a dois numa relação de constante troca.

A abordagem empregada foi a do estudo de caso e a coleta de dados realizada por meio de análise documental, observação participante, entrevistas informais, entrevista gravada e conversas por telefone. Em todas as ocasiões a aluna demonstrou a maior boa vontade de responder às minhas perguntas. $\bigcirc$ que ela tinha diante de si era uma professora que gostava de conversa e que esmiuçava sua vida para além do que se entende como estritamente acadêmico, e encarou esse interesse de maneira tranqüila, natural e alegre.

I. Programa de Educação Continuada/Formação Universitária: programa educacional promovido entre junho 200 I a dezembro 2002 pela Secretaria da Educação do Estado de São Paulo em parceria com a Universidade de São Paulo - USP -, a Universidade Estadual Paulista Unesp e a Pontifícia Universidade Católica de São Paulo - PUC/SP. O objetivo foi atender à Lei de Diretrizes e Bases da Educação Nacional que prevê a formação em nível superior, dentro de cinco anos, para todos os professores do ensino fundamental. As aulas eram ministradas por videoconferências (duas vezes por semana), teleconferências (quinzenalmente, transmitidas ao vivo pela TV Cultura de São Paulo), e transmitidas pelos Centros de Formação e Aperfeiçoamento do Magistério - Cefams - em 34 locais do estado pela internet e intranet. A matriz curricular era formada por eixos temáticos em vez de disciplinas, e o trabalho (carga horária de doze a dezesseis horas semanais) monitorado de perto por um tutor e, on-line, por professores assistentes. Participei do projeto como orientadora de TCC e videoconferencista. 


\section{O ESTUDO DE CASO}

O estudo de caso insere-se no contexto das metodologias etnográficas. A etnografia educacional tem como pressuposto básico a existência de um "conflito cultural” - significados, valores, articulações, práticas e formas simbólicas representativas de grupos que num dado momento (ou aspecto) são antagônicos. O cultural é visto "como o produto da práxis humana coletiva" (Willis, 199|, p. | 4). Neste estudo o conflito cultural é representado pelo choque entre duas visões de mundo: de um lado, a professora encastelada nas teorias e limites da academia, com dez anos de afastamento da sala de aula; do outro, uma professora da escola básica, impregnada de prática, mas ainda sem nenhuma noção das teorias educacionais vigentes.

O importante num estudo etnográfico é interpretar o fenômeno estudado a partir de suas relações com o contexto social mais amplo e não apenas em razão das relações internas. Metodologicamente, isso implica complementar a informação de campo com informação relativa a outras ordens sociais, e buscar interpretações e explicações com base em elementos externos à situação particular (Rockwell, Ezpeleta, 1989).

Para Yin (200 I), um estudo de caso investiga um fenômeno contemporâneo dentro do seu contexto da vida real, especialmente quando os limites entre o fenômeno e o contexto não estão claramente definidos. Num estudo de caso formulamos três questões principais: I. quais as fontes de dados utilizadas e como esses foram coletados? 2. como os dados foram verificados e confirmados? 3. como os dados foram interpretados, e como se chegou a determinados julgamentos e conclusões? Acrescento ainda uma quarta pergunta: por que o pesquisador se interessou por este determinado caso? $\bigcirc$ que $\circ$ levou ao tema?

Como fontes de evidência utilizei documentos, observação participante e entrevista. Dentre os documentos examinados destaco o próprio TCC de Marlene, seus trabalhos para o PEC, inclusive memórias em que ela relata a vida pessoal, que não serão divulgadas mas que serviram como pano de fundo para minhas interpretações. Os dados da observação participante foram registrados após um certo momento, quando percebi ter ali um caso. A entrevista foi realizada no final do trabalho e serviu para que eu organizasse idéias e preenchesse lacunas: pedi que ela repetisse o que tinha dito em sala de aula, que 
contasse mais detalhes sobre sua convivência diária com os buracos da lousa e com o processo de escrever um TCC sobre tal experiência. Além das duas horas de entrevista gravada, tivemos várias conversas por telefone. Embora para Yin (200 I) o artefato físico tenha uma importância potencialmente menor na maioria dos estudos de caso, a lousa esburacada - que só vi em fotografias foi um componente essencial tanto para a pesquisa de Marlene quanto para o meu estudo. Ao final, enviei o relatório para que ela o examinasse. Seus comentários foram incorporados à versão final.

Quanto ao meu interesse pelo tema, deve-se não só pelo que ele tem de inusitado, de diferente, como também porque o "mundo-da-vida" (Habermas, 1991) da escola é fonte de oxigênio para minha pesquisa, por isso, de tempos em tempos, tenho de voltar lá. Precisamos estar atentos para não cair na tentação de ditar normas, criticar e propor soluções unilaterais à escola, sem estar em contato direto com seu mundo. Durante recente pesquisa desenvolvida na rede pública do interior de São Paulo (Machado, Cunha, 2003), professores se queixaram da relação pouco respeitosa que às vezes existe entre a universidade e a escola. Por isso estavam pensando em criar um núcleo de triagem para selecionar os projetos de pesquisa que necessitassem de trabaIho de campo dentro da escola: só poderiam ser desenvolvidos aqueles que interessassem à comunidade escolar e os resultados só seriam divulgados após passar pelo seu escrutínio. Esse problema ilustra a distância que se pode estabelecer entre teoria e prática, com igual responsabilidade dos dois lados, pois a escola também rejeita a teoria com a alegação de que na prática ela não funciona, embora isso tenha melhorado sensivelmente mediante os cursos de capacitação.

\section{O fio da meada}

mais difícil num relatório de estudo de caso é organizar os dados e transformá-los num texto linear, sobretudo porque, nesta pesquisa, não fui eu quem escolheu o tema mas o próprio tema se impôs e por isso não recolhi dados de forma sistemática desde o início. $\bigcirc$ que passo a relatar são as informações coletadas na observação participante (durante as sessões de orientação), nas conversas informais, na entrevista gravada e nas conversas telefônicas, informações estas às quais procurei dar uma seqüência lógica. 
Na primeira sessão de orientação coletiva (agosto de 200 I), nem percebi a presença de Marlene na sala lotada (uma turma só de mulheres). $O$ propósito do encontro era dar as primeiras noções de como escolher um tema de pesquisa para os TCCs. A finalidade do TCC foi explicitada no documento A produção do trabalho de conclusão de curso, divulgado pelo PEC: possibilitar ao aluno-professor, por um lado, a experimentação de procedimentos de investigação acadêmico-científicos e, por outro, revisitar o universo escolar e a prática pedagógica a partir de um olhar distanciado, possibilitado pelos procedimentos de investigação. Pedi então às alunas-professoras que observassem suas escolas e apontassem um problema que fosse digno de ser pesquisado. Assumi como certa a compreensão do conceito de problema e marcamos o próximo encontro.

Na sessão seguinte tivemos um rol bastante variado de assuntos que as alunas foram enumerando: indisciplina, agressividade, avaliação, progressão continuada, inclusão, fracasso escolar, desenvolvimento da leitura, dislexia. Três alunas perguntaram se podiam desenvolver temas que se originavam de experiências marcantes em suas vidas. Uma delas interessou-se por estudar dislexia, porque seu filho era considerado disléxico; outra resolveu abordar o tema da inclusão não só pela mudança na legislação educacional, que coloca na mesma classe alunos com e sem necessidades especiais, como também porque tem dois filhos com síndrome de Down; uma terceira decidiu abordar a inclusão a partir da ótica do superdotado porque seu filho foi assim classificado; enfim, já de início passei por momentos em que tinha de julgar, aceitar e orientar temas que ignoravam fronteiras entre o profissional e o pessoal, entre o objetivo e o subjetivo, entre a ciência e a vida.

Marlene foi a última a falar. Timidamente levanta-se e profere a frase que deixou a todos atônitos: seu problema eram os buracos da lousa. Respirei fundo, anotei o tema e pensei que devia voltar a ele para mais esclarecimentos. Quinze dias depois decidi contornar a situação, sugerindo algo diferente. Perguntei-Ihe o que mais ela considerava problema, se havia olhado bem ao redor, perguntado aos colegas e se finalmente havia concluído que "os buracos da lousa eram o que havia de mais relevante". Expliquei, mais uma vez, o que se entendia por problema de pesquisa, exemplifiquei com outras pesquisas já realizadas, sempre com a preocupação de não deixá-la em posição desconfortável. No intervalo, suas colegas tentaram demovê-la, mas ela insistiu nos bu- 
racos da lousa. Foi então que percebi não estar diante de algo tão simples: ela havia escolhido o tema, baseada numa sondagem entre os alunos, pois só assim achou que seria possível detectar aquilo que realmente os afligia. Não podia mudar de tema, pois se o fizesse, disse, "não estaria sendo leal com aqueles que haviam ajudado no levantamento".

Intuitivamente, Marlene havia realizado uma "etnografia prévia" (Guba, Lincoln, 1989, p.20I) que exige a vivência no contexto durante algum tempo como observador participante, consultando membros do grupo local para detectar seus interesses e expectativas. $\bigcirc$ que mais afetava às crianças de sua $2^{\text {a }}$ série, e a ela em particular, eram os buracos da lousa. A camada de alvenaria se havia deteriorado por causa de uma infiltração no teto da sala de cima e tanto a tinta quanto o reboco estavam caindo aos pedaços. Ao escrever uma frase, a professora tinha de realizar verdadeiros malabarismos para contornar os buracos da lousa. O resultado final era um emaranhado de letras, frases e curvas que deixavam as crianças impacientes, inquietas e frustradas. A aula era um desastre.

Como orientadora, a princípio pensei o quão difícil seria chegar a uma monografia a partir da lousa danificada, especialmente porque Marlene estava irredutível. As coisas pioraram ainda mais quando, na sessão seguinte, perguntei a todos como andava o amadurecimento dos temas e Marlene veio muito entusiasmada me dizer que os buracos da lousa tinham direta relação com a globalização. Decidi ganhar tempo e pedi à Marlene que elaborasse seu pensamento um pouco mais e apresentasse algumas idéias no próximo encontro. Minha esperança era mais uma vez que ela desistisse da empreitada.

Felizmente ela resistiu às minhas expressões de desespero, incredulidade e desânimo e, na sessão seguinte, esclareceu que realmente aquele seria seu tema, pois ao realizar um trabalho do PEC denominado Vivência pedagógica: roteiro de pesquisa da realidade escolar - em que teve de coletar dados relativos à escola quanto a sua história, organização, recursos físicos, bairro no qual está inserida, corpo docente, equipe dirigente, progressão escolar dos alunos, nível de organização dos diferentes segmentos e condições socioeconômicas dos alunos - começou a observar que as carteiras estavam quebradas, pichadas, o prédio depredado e que "os buracos eram um fiozinho do que havia mais à frente. Tinha muito mais coisas do que se imaginava no começo".

Mas qual a relação entre os buracos da lousa e a globalização? Perguntei-Ihe. Em que sentido o fenômeno dos buracos da lousa tem a ver com a 
relação entre os países? Quem influenciou o quê? Voltei à carga. Sua resposta veio bem mais estruturada. Acho que foi nesse momento que senti estar diante de algo intrigante, digno de ser registrado. Mais tarde, na entrevista gravada, pedi-Ihe que repetisse a resposta na qual ela estabelecia a relação entre os buracos da lousa e a globalização. Eis a resposta:

A escola não existe somente no país, mas em vários países. A gente não deve pensar somente no Brasil, pois a sociedade hoje é globalizada. Sabe-se tudo de maneira imediata. A gente está ligada em uma rede, internet, meio de comunicação e os problemas de um país que está longe interferem no nosso, na bolsa, no estudo, em tudo. Hoje o professor quando entra na sala não deve imaginar que está ensinando o aluno só para aquilo: é preciso ajudar a criança a pensar no todo... [A lousa] passou por um processo pra chegar àquela degradação. Ele veio da lousa de cima e acabou na minha sala, mas antes disso alguém não pensou em resolver o problema da infiltração...

E por que não se resolveu o problema da infiltração? Perguntei-lhe. A diretora viu, mandou ofício, mas existe muita burocracia para chegar até a pessoa que tem de assinar. É preciso fazer uma licitação, um processo muito demorado.

Ao ver a lousa tão deteriorada, os alunos dos três turnos deixavam-se tomar por um sentimento de "já que ninguém manda consertar, vamos destruir o resto" e se divertiam arrancando pedacinhos da pintura e do reboco. Por isso, na visão de Marlene, tanto o poder público como os usuários da escola são vândalos: a omissão, o descaso na falta de manutenção encontram resposta imediata na ação, no vandalismo. Vandalismo e descaso alimentamse mutuamente, dando ao cenário um aspecto de terra arrasada.

O vandalismo não acontece só no Brasil. Acontece em outros países. Em várias atitudes que as pessoas tomam. A pessoa pensa que o que ela fez não vai interferir em outros lugares, mas interfere muito. $O$ atentado das Torres Gêmeas afetou a sala de aula, as crianças ficaram mais agitadas, comentaram. Ninguém está mais isolado. O que é vandalismo aqui agora é vandalismo em outro lugar. As crianças reagiam aos buracos ficando agitadas, levantando e falando: "Professora, não entendo o que está escrito". Elas começavam a cutucar-se umas às 
outras, a falar mais alto, a bater umas nas outras. As atitudes delas demonstravam estarem transtornadas com a lousa e não tinham em quem descontar, dar o troco. Descontavam em quem estava mais próximo: a carteira, a cadeira, a mesa, o colega. A vida é como um dominó: uma coisa acontece aqui, esse dominozinho vai derrubar o próximo e vai crescendo.

Para Marlene, vândalos são os que quebram e destroem um bem público e também os que picham os muros e edifícios. Perguntei-lhe como havia chegado aos pichadores.

Foi muita curiosidade. Eu não me conformava com as carteiras pichadas e dentro de mim eu pensava: se consigo ensinar a uma criança a ler, decifrar aquele mundo letrado, decodificar aquelas letras, juntar, formar palavras, se consigo fazer isso, como é que não consigo ler o que está escrito lá com piche? Eu decidi ir atrás de quem faz isso para entender como ele pensa. Porque não me adianta ficar pensando sozinha. É uma pessoa só. Fui então atrás deles: o que é uma pichação, qual a diferença entre uma pichação e um grafite? Uma amiga me disse que conhecia uns pichadores na escola onde ela trabalha e eu pedi que marcasse uma entrevista com eles. Será que o diretor deixa? Vou tentar... Peguei uma folha, fiz um questionário... Eles então escreveram o que eles sentiam e eu fiquei mais intrigada com as respostas que eles me deram e fui pedir a eles que traduzissem o que eles tinham escrito. Como se chamavam aquelas letras? ...Descobri então como eles eram, onde viviam, são crianças muito pobres, geralmente de pais separados, têm sempre alguém na família que está preso ou se prostitui. Eles não têm onde descontar nada do que têm dentro deles. A primeira coisa que eles encontram vão pichando... é uma forma de botar para fora aquilo que dói mais. Interessante como criam aquelas palavras, aqueles códigos. Só eles entendem e somente aqueles pichadores que eles querem que leiam. $\bigcirc$ professor que passa, eles querem que pense que aquilo lá é só um borrão. Não querem que a gente entenda o que está escrito. Os de outros grupos têm um certo respeito por aquele que pichou. Se alguém picha por cima, é porque existe briga entre eles.

Por que os pichadores não querem que as outras pessoas entendam o que eles escrevem? 
Creio que é uma maneira de, perante a sociedade, se sentirem os poderosos. Eu faço e você não lê. Eu sou acima de você porque você não lê. É deles, entre eles porque eles são muitos. Entre eles existe uma pasta; cada um tem o seu código e cada código só o colega sabe ler. Eles não querem que a sociedade leia o que eles escrevem. Eles não têm nada, nenhuma infra-estrutura: uma casinha bem pequena, o local para higiene é micro, um cômodo para tudo. $\bigcirc$ vandalismo tem a ver com as condições de vida dessas crianças.

Grande parte do TCC de Marlene é dedicada às idéias de Michel Foucault provenientes do livro Vigiar e Punir (2000), por isso perguntei-Ihe como havia chegado a esse autor.

Eu li um texto da Áurea Guimarães de 1985 na biblioteca da Unicamp. A Áurea fala dos prédios escolares e do Foucault. Então fui ler o Foucault e gostei muito. $\bigcirc$ homem é um gênio. $O$ que ele falou sobre os séculos XVI, XVII é do mesmo jeito até hoje: o corredor, uma porta, no meio tem uma mesa; os alunos, prisioneiros e o vigia olhando todo mundo, as janelas altas, grades, chaves, correntes cadeados. Hoje em dia o ser humano está ficando cada vez mais enjaulado, como vivendo em prisões. Eu achei o Foucault um gênio. Ele fala muito sobre prisões, sobre o controle que o ser humano tem sobre o corpo da outra pessoa. E ele está certo em tudo o que fala. $\bigcirc$ que ele usa para as prisões, se você prestar atenção, aplica-se à sala de aula. Quando ele fala sobre os prédios ele fala sobre a estrutura das prisões, como constroem as prisões. Ele dizia que era para trancar um louco, um doente e um aluno. Você coloca lá um guarda, um mestre, um vigia. Do jeito que ele colocou as prisões, as escolas são construídas assim mesmo.

Como Goodson ( 1995), acredito que para entender a prática do professor, precisamos saber mais sobre suas vidas pois "o aspecto pessoal apresenta-se irrevogavelmente associado à prática. É como se o professor fosse a sua própria prática" (p.68). O que me interessava era conhecer mais a fundo alguém que, com tão pouco acesso aos livros, jornais e revistas, havia agarrado com unhas e dentes a oportunidade que lhe era oferecida para aprender e se qualificar, saindo por aí, buscando, de maneira incansável e apaixonada, in- 
formações sobre seu tema de pesquisa. Minha preocupação era "com o cantor e não com a canção" (p.67). Entendendo o cantor, eu tiraria conclusões úteis para aperfeiçoar também a minha canção. Marlene assim se descreve:

Sou muito simples e tenho um defeito: sou curiosa demais. Eu nunca me conformo com uma resposta que uma pessoa me dá. Jamais. É realmente aquilo? Eu nunca vou pela primeira resposta que me dão. Eu acho que a pessoa quando fala, ela tem um lado psicológico. Eu nasci no interior de São Paulo, fiquei lá quatro ou cinco anos e depois fui para a capital.

Como você se tornou professora? Perguntei-Ihe.

Eu sempre gostei muito de criança, mas esse não era o meu sonho: eu queria ser administradora de empresas. Mas fiz o curso de técnico em administração. Estava estudando administração, mas os meus pais tiveram de se mudar para um local mais longe, fui fazer o magistério. Quando eu entro na sala de aula tem gente que reclama de salário, está certo é um direito reclamar - mas quando eu entro em sala de aula eu sou a professora, ele é meu aluno e eu acho que se a criança tem piolho ou um problema maior, eu ganho pra ensinar a ela, ela é muito importante para mim. Eu tenho muito carinho pelos meus alunos e fico indignada quando falam mal de uma criança perto de mim. Eu quero morrer. Eu penso que se não quer cuidar de uma criança, escolha outra profissão. Se você pensar bem, o professor precisa daquela criança. Eu entrei numa escola do estado após terminar o magistério e fui trabalhar como inspetora de alunos. Aí comecei a observar mais ainda pois eu tinha muito mais liberdade que o professor. Eu fui entender como elas pensam. Eu tinha um espaço livre porque eu conversava muito mais com as crianças. Eu descobri histórias que eram maraviIhosas ou muito tristes. Eu cheguei a ver casos de pessoas que não servem para cuidar de crianças.

\section{CREDIBILIDADE E VALIDADE NUM ESTUDO DE CASO}

A credibilidade e a validade interna e externa de um estudo de caso constituem o seu maior problema por causa da potencial subjetividade do in- 
vestigador. Yin (200I) discute a questão da validade e apresenta quatro testes que são comuns aos métodos de ciências sociais:

a. validade do constructo: se foram utilizadas várias fontes de evidência; se é estabelecido um encadeamento das evidências e se o rascunho do relatório é revisado por informantes-chave;

b. validade interna: se as inferências são corretas; se todas as possibilidades foram consideradas; se as evidências são convergentes;

c. validade externa: se as descobertas do estudo são generalizáveis;

d. confiabilidade: se um pesquisador seguir exatamente os mesmos procedimentos descritos por outro que veio antes dele e conduzir o mesmo estudo de caso, chegará às mesmas conclusões.

Nossos procedimentos atendem à validade de constructo. Segundo Yin (apud Tellis, 1997), podemos testar a validade interna do estudo pela análise pattern-matching - uma comparação entre o padrão empírico e o predito. $\bigcirc$ estudo terá maior validade se os padrões coincidirem. Se o estudo de caso é do tipo explanatório, os padrões devem ser relacionados às variáveis dependentes ou independentes. Se for um estudo descritivo, o padrão predito deve ser definido antes da coleta de dados. Para alguns autores, credibilidade e validade são pseudoproblemas; afinal esses critérios partem do princípio de que só podemos considerar algo como verdade se esse algo puder ser comparado e medido com relação a uma outra verdade estabelecida, o que foge totalmente dos objetivos de uma pesquisa interpretativa como o estudo de caso.

Entretanto, tentando obedecer ao padrão de análise pattern-matching, poderíamos enumerar algumas características da maioria de nossos alunos-orientandos e dizer "o quanto" e "em que" nosso caso se diferencia da maioria. Para obter uma descrição detalhada do que se poderia considerar um aluno médio, é preciso um longo e profundo estudo etnográfico de diferentes populações. Prefiro registrar no que vejo o meu caso como diferente. Segundo Greenfield (apud Evers, Lakomski, 1991), o conhecimento significativo da realidade, natural ou social, contém um componente subjetivo irredutível. Para esse componente subjetivo é difícil portanto encontrar um padrão ao qual ele se assemelhe.

Ao testarmos a validade interna do estudo pelo pattern-matching, pomos em perigo a espontaneidade e o inesperado do empírico, portanto, arris- 
co afirmar que o problema foi identificado via "conhecimento tácito", um conhecimento pré-científico hoje incorporado à pesquisa educacional e definido por Polanyi ( 1967 ) como intuições, apreensões, sentimentos que não podem ser expressos em palavras, mas que de alguma forma são conhecidos pelo sujeito: é tudo o que sabemos subtraindo tudo o que podemos dizer.

Talvez a análise do tipo pattern-matching possa ser utilizada para identificar tipos culturais - por exemplo, o que distingue um brasileiro de um português, ou de um peruano, ou de um francês. Tais identidades culturais são engendradas pelas estruturas sociais e são reconhecíveis em casos individuais. Nesse sentido é possível afirmar que um brasileiro tem identidade diferente daquela de um francês, um diretor de empresa não se confunde com um vagabundo, um habitante da cidade difere de um habitante do campo, um nordestino, de um sulista. Os tipos de identidade podem ser observados na vida cotidiana e suas diferenças, verificadas. "Os tipos de identidade são observáveis, verificáveis na experiência pré-teórica, e pré-científica” (Berger, Luckman, 1985, p.229). Para Yin (1994, apud Tellis, 1997) a validade externa deve ser verificada analisando se os resultados são generalizáveis para além do caso imediato.

Os estudos mais criticados, pela sua pretensa falta de validade externa, são os casos individuais, como o que tomamos para exame. Entretanto, o que queremos justamente ressaltar é o dado singular - que pode ser definido como aquele que se sobressai dentro das regularidades que caracterizam o conjunto a ser analisado, o diferente, o que foge à regra, tendo por isso a possibilidade de revelar um modo de atuação mais esclarecedor. Ao julgar a relevância e pertinência de casos individuais como este, há o perigo de nos impregnarmos de pressupostos de teorias obsoletas que às vezes descartam experiências únicas e singulares porque não consideradas científicas. Por isso sugiro que a validade externa deste estudo de caso seja justamente a particularidade do problema: após muitos anos de experiência como pesquisadora e professoraorientadora, vi-me diante de um caso que não consegui comparar com nenhum outro conhecido e que me fez parar para pensar em várias questões relacionadas à profissão. Em outras palavras, atribuir a um estudo de caso como este o certificado de validade externa significa admitir que a particularidade é tão válida quanto a generalidade e que em educação devemos estar cada vez mais atentos às singularidades - o que o estudo de caso destina-se a detectar - a fim de fugirmos da homogeneização e da massificação. 
O produto final de um estudo de caso é um relatório de caso. Segundo Guba e Lincoln (1989), um relatório de caso não apresenta um estado de coisas "real" ou "verdadeiro" nem uma série de generalizações que possam ser aplicadas a outros ambientes. $\bigcirc$ relatório de caso ajuda o leitor a compreender não só o estado de coisas que os participantes acreditam existir como também os motivos, sentimentos e bases lógicas que os fazem assim acreditar. Ele torna possível ao leitor vivenciar vicariamente o processo. A experiência vicária é crucial porque o mecanismo básico da aprendizagem dos seres humanos é a experiência: é por via desse processo que o conhecimento ideográfico (nãogeneralizável) pode ser aplicado num segundo ambiente. $\bigcirc$ relatório de caso é portanto um grande veículo para a disseminação, aplicação e agregação (individual) de conhecimento.

\section{CONHECIMENTO A DOIS}

Segundo Ferrarotti (1983), o conhecimento sociológico na pesquisa biográfica é um conhecimento a dois. Para convencer alguém a contar sua vida pessoal, o pesquisador dispõe de ao menos dois argumentos: ele deve garantir ao respondente o completo anonimato e prometer-lhe que seus esforços servirão para alguma coisa. No caso de minha aluna-respondente, não se tratava de sua vida pessoal. $\bigcirc$ que a fez concordar em se transformar em um estudo de caso foi a vontade de compartilhar com outras pessoas uma experiência extremamente importante em sua vida profissional e que the trouxe bons resultados ${ }^{2}$. Nosso estudo de caso revelou-se um conhecimento a dois porque, a partir da relação orientador-orientando, a aluna e eu aprendemos muito sobre educação em geral e sobre como fazer pesquisa.

Num estudo de caso o pesquisador tem de estar ciente de alguns elementos básicos citados por Yin (200I, p.8I), a fim de conduzir sua pesquisa com relativo sucesso. Devemos:

2. Em suas próprias palavras, foi graças ao PEC que ela foi aprovada num concurso público no Estado de São Paulo e está feliz ensinando numa escola mais perto de casa, onde a vêem com admiração. 
a. ser capazes de fazer boas perguntas e interpretar as respostas;

b. ser bons ouvintes e não ser enganados por nossas próprias ideologias e preconceitos;

c. ser adaptáveis e flexíveis, de forma que as situações recentemente encontradas possam ser vistas como oportunidades e não como ameaças;

d. ter noção clara das questões que estão sendo estudadas e focar os eventos e informações relevantes;

e. ser imparciais em relação a noções preconcebidas, incluindo aquelas que se originam de uma teoria, e, portanto, sensíveis e atentos a provas contraditórias.

Tivesse eu conhecido essa lista do Yin antes, com certeza minha pesquisa teria sido bem melhor. Nossa relação orientador-orientando aprofundou-se lentamente. Como a própria aluna admite, tivesse sido eu irredutível, ela teria desenvolvido um outro tema, revoltada. Não seria o tema pelo qual tinha tanta paixão. Sinto que estive a ponto de desencorajá-la e a sensação é de que, por pouco, não caí na cilada de determinar, descuidada e preconceituosamente, a irrelevância de um tema. De certa forma acabei cumprindo a exigência de flexivilidade feita por Yin, pois a situação encontrada tornou-se uma oportunidade e não uma ameaça. Quanto às perguntas, elas foram feitas de ambas as partes: ela me perguntava sobre globalização, sobre Foucault, e eu, sobre suas mais recentes conclusões a respeito de violência, vandalismo, escola, mundo.

Para ilustrar a relação orientador-orientando, Marlene usou outra metáfora: é como uma criança que está engatinhando e depois começa a andar.

Agora eu ando. No começo do trabalho pensei até em desistir do PEC porque eu não conseguia desenroscar isso. Mas muitas vezes é uma palavrinha que coloca tudo no eixo de volta e você vai embora. Você sente vontade de pesquisar mais. Você às vezes pensa em ir em linha reta mas não existe só a linha reta no trabalho: existem os outros pontos. Você tem ajuda de muita gente para chegar ao final.

Ao nos impregnarmos de teoria, perdemos o sentido do micro. A teoria, quando só, acaba nos fazendo perder a ligação com o contexto e a visão macro tem o defeito de ignorar o elemento humano do cotidiano, de desprezar o conhecimento tácito. 
Se toda pesquisa começa de um problema, e ela só é bem-sucedida e original se o problema for bom e original, como podemos distingui-lo? Polanyi considera que um problema é algo escondido. Ele indica a coerência de particulares não compreendidos até então. "Ver um problema que levará a uma grande descoberta não é somente ver algo escondido, mas ver algo que o resto da humanidade não tem a mínima noção" (1967, p.21). O conhecimento tácito indica algo que ainda está para ser descoberto, portanto é necessário que não ignoremos o conhecimento prévio de coisas ainda não descobertas. Sabemos mais do que podemos expressar com palavras, afirma Polanyi. Aquilo que pode ser transformado em linguagem é o "conhecimento proposicional". O conhecimento tácito indica de antemão que ali há um problema a ser investigado e o conhecimento proposicional formula a hipótese.

Como não temos nenhum conhecimento explícito das coisas, também não pode haver nenhuma justificativa explícita de uma verdade científica. Mas assim como podemos conhecer um problema, e nos sentir seguros de que aponta para algo escondido por trás dele, podemos estar conscientes também das implicações de uma descoberta científica, e confiar que elas podem ser demonstradas. Somos permanentemente guiados pela busca da descoberta, pela sensação da presença de indícios. A descoberta satisfaz essa busca. Ela reivindica ter feito contato com a realidade, uma realidade que pode ainda revelar uma série de manifestações inesperadas no futuro.

Para Polanyi ( 1967) o conhecimento tácito pode dar conta: I . do conhecimento válido de um problema; 2 . da capacidade do cientista de buscá-lo, guiado pelo seu senso de aproximação da solução; 3. da antecipação válida de implicações ainda indeterminadas da descoberta atingida no final. $\bigcirc$ conhecimento tácito é pessoal no sentido de envolver a personalidade daquele que o possui, e também no sentido de ser, na maioria das vezes, solitário. $\bigcirc$ descobridor carrega um sentimento de grande responsabilidade pela busca de desvendar uma verdade.

A antecipação da descoberta, como a própria descoberta, pode vir a ser uma desilusão. Mas é inútil procurar critérios de validade estritamente impessoais, como a filosofia da ciência positivista tem tentado fazer nos últimos cem anos. As coisas das quais tomamos conhecimento tacitamente são problemas, pressentimentos, fisionomias e habilidades, o uso dos instrumentos, sondagens, linguagem denotativa e até o conhecimento primitivo de objetos externos per- 
cebidos por nossos sentidos. Seguimos expandindo nosso corpo pelo mundo, formando, intelectual e praticamente, um universo interpretado, povoado por entidades cujos particulares interiorizamos com a finalidade de compreender seu significado de forma coerente.

Temos em Marlene uma pesquisadora iniciante que descobre um problema, a princípio tão pequeno e irrelevante para os outros, e que chega a conclusões que por certo modificarão a sua prática e a de quem a ouvir. Eis a materialização do professor-reflexivo de Shön (1983), numa concepção que incorpora o conhecimento tácito, valoriza a prática e mostra como a reflexão propicia o desenvolvimento do saber. Schön chama a atenção para o papel da observação e da reflexão na prática profissional e para os limites do pensamento acadêmico. A prática reflexiva consiste em um processo de investigação na ação mediante métodos etnográficos e qualitativos: aprende-se fazendo e refletindo na prática e sobre a prática.

\section{CONSIDERAÇÕES FINAIS}

Santos (200I) afirma que, diante da ambigüidade e complexidade do tempo presente, faz-se necessário voltar às coisas simples, à capacidade de formular perguntas simples. Inspirado no "Discours sur les sciences et les Arts", de Rousseau (197|), Santos (200 I, p.8) nos convoca a

... perguntar pelas relações entre ciência e virtude, pelo valor do conhecimento dito ordinário ou vulgar que nós, sujeitos individuais ou coletivos, criamos e usamos para dar sentido às nossas práticas e que a ciência teima em considerar irrelevante, ilusório e falso.

Kleiman e Moraes ( 1999 ) observam a existência de um embate constante entre as visões micro e macro: "enquanto o educador lança seu olhar na paisagem sem ver a pedra no caminho, o lingüista ${ }^{3}$ pode esquecer a paisagem por causa da forma, cor e tamanho da pedra que chamou a sua atenção" (p. I l).

3. Agradeço a Professora Angela Kleiman, lingüista, especializada no ensino da leitura, as críticas e sugestões feitas a este texto. 
No caso do trabalho de Marlene, procurei relacionar esses dois pólos: o micro materializa-se nos buracos da lousa, o macro, no problema socioeconômico que ocasiona o vandalismo escolar. É a mesma simbiose, que não deve ser quebrada, entre o local e o global, o individual e o coletivo, o subjetivo e o objetivo, o profissional e o pessoal, entre ciência e vida.

O produto, o TCC, é de extrema relevância tanto para a aluna-pesquisadora quanto para a comunidade em que ela atua: a aparência deplorável de uma escola estadual na periferia de Sumaré (município próximo à Campinas, no Estado de São Paulo) provocou nela uma atitude reflexiva e a busca de possíveis soluções para o problema. Ela então se pergunta:

...em meio a tanto vandalismo na sociedade seria possível obter-se uma escola organizada para a boa execução do trabalho escolar? Como agir com crianças que, de certa forma, parecem indisciplinadas sem recorrer ao círculo das punições e ameaças? Como conduzir tais crianças ao exercício da cidadania?

Inspirada em Foucault (2000), ela tece considerações a respeito de o que fazer com os vândalos e por que eles se tornam vândalos.

Embora reconhecendo a importância do tema vandalismo escolar e o esforço e o resultado do trabalho da aluna, neste estudo salientamos, entretanto, o processo pelo qual se construiu um conhecimento teórico-prático tão peculiar e tão necessário à área educacional. A aluna partiu de um tópico (do grego tópikos - "local"), os buracos da lousa, para chegar a um tema (do grego théma - "proposição"), vandalismo escolar. Ela puxou o fio da meada, teceu uma rede de conexões e relações do tópico com o contexto e construiu um cenário onde impera a exclusão, a revolta dos invisíveis.

Dentro da perspectiva contemporânea de desenvolver no currículo o diferente e o único - de acordo com as novas teorias curriculares como, por exemplo, a Teoria das Inteligências Múltiplas, de Gardner (1995) - vejo o estudo de caso como uma contribuição para que nós professores possamos identificar, valorizar e aceitar o outro, "que se revela realmente como outro, em toda acuidade de sua exterioridade, quando irrompe como o mais extremamente distinto, como o não habitual ou cotidiano, como o extraordinário, como o enorme (fora de norma), como o pobre, o oprimido" (Dussel, s.d., p.54). 
Como afirma Doll Jr. (1999), somos o outro do outro e o nosso sentido de selfdefine-se em termos da relação outro-outro. Oculto sob o que podemos chamar de doces sonhos da razão, espreita um lado inferior, obscuro, uma tendência violenta a reduzir ou assimilar o outro ao mesmo, colonizando, apropriando-se de, controlando, dominando, anulando, subjugando o que se apresenta como o outro. Bernstein vai ainda mais longe; ao referir-se aos trabalhos de Levinas (1988) e seu pupilo, Derrida (1995), argumenta que há um sentido básico não somente de diferença entre o selfe o outro mas também de incomensurabilidade do outro. "O que está em questão aqui é o reconhecimento da radical singularidade incomensurável do outro (l'autri), de recuperar um sentido de radical pluralidade que desafia qualquer reconciliação total fácil" (Bernstein, 1992, p.7I). Afirma ainda, em resumo, "há tanto a similaridade quanto a radical alteridade, a simetria e a assimetria, a identidade e a diferença na minha relação com o outro, e acima de tudo na relação ética" (p.72). Portanto, precisamos cultivar o tipo de imaginação que nos torna ao mesmo tempo sensíveis à semelhança do outro com nós mesmos e à radical alteridade que desafia e resiste à redução do outro ao mesmo.

E o que isso causa aos nossos conceitos de educação e ética? Tanto a ética quanto a educação, imbuídas da razão modernista, assumem a "nossa" justiça, a "nossa" correção, levando o outro a ser julgado como o bárbaro ou o desencaminhado. Agora, em nossa era pós e global, Doll Jr. (1999) apela para uma nova consciência que lide com a responsabilidade de, como humanos, honrarmos a singularidade de todos. Isso muda a perspectiva da ética e da educação de "um/ou" para "ambos/e". Nosso sentido de relação muda da dicotomia nós/ eles para uma outra em que honramos ambos, o mesmo e a alteridade.

E quanto à lousa? Ah! A lousa! Marlene esclarece que a "lousa, que nos levou a este trabalho de conclusão de curso, assim como a escola inteira, passou por uma reforma geral, que vai desde consertos até construção e pintura". Mas, como foi demonstrado, a solução para os buracos da lousa não está somente nas mãos do pedreiro e do pintor.

\section{REFERÊNCIAS BIBLIOGRÁFICAS}

BANES, M. Vandalismo escolar. Rio Claro, 2002. TCC. Lic. Pedagogia. PEC.

BERGER, P.; LUCKMAN, T. A Construção social da realidade. Petrópolis: Vozes, 1985. 
BERNSTEIN, R. The New constellation. Cambridge, MA: MIT Press, 1992.

DERRIDA, J. The Gift of death. Chicago: University of Chicago Press, 1995. [Tradução de D. Wills.]

DOLL JR., W. E. Conversion with "the Other". Journal of Curriculum Theorizing, v. I 5, n.3, p.83-90, 1999.

DUSSEL, E. Filosofia da libertação: filosofia na América Latina. São Paulo: Loyola, s.d.

EVERS, C.; LAKOMSKI, G. Knowing educational administration. Sydney: Pergamon Press, 1991.

FERRAROTTI, F. Histoire et histoires de vie. Paris: Librairie des Meridiens, 1983.

FOUCAULT, M. Vigiar e punir. nascimento da prisão. Petrópolis: Vozes, 2000. [Trad. Lígia M.P. Vassalo.]

GARDNER, H. Inteligências múltiplas. a teoria na prática. Porto Alegre: Artmed, 1995.

GOODE \& HATT, K. Métodos em pesquisa social. São Paulo: Cia. Editora Nacional, 1968.

GOODSON, I. Dar voz ao professor: as histórias de vida dos professores e o seu desenvolvimento profissional. In: NÓVOA, A. Vidas de professores. 2.ed. Porto: Porto Editora, 1995. p.63-78.

GUBA, E.; LINCOLN, Y. Fourth generation evaluation. Newbury Park, London, New Delhi: Sage, 1989.

GUIMARÃES, A. M. Vigilância, punição e depredação escolar. Campinas: Papirus, 1985.

HABERMAS, J. Theory of communicative action, lifeworld and system: a critique of functionalist reason, v.2. Boston: Beacon Press, 1991.

KLEIMAN, A.; MORAES, S. E. Leitura e interdisciplinaridade: tecendo redes nos projetos da escola. Campinas: Mercado de Letras, 1999.

LEVINAS, E. Totalité et infini : essai sur l'exteriorité. Dordrecht: Kluwer Academic Publishers, 1988.

LÜDKE, M.; ANDRÉ, M. E. D. Pesquisa em educação: abordagens qualitativas. São Paulo: EPU, 1986.

MACHADO, N.; CUNHA, M. (orgs.) Linguagem, conhecimento, ação: ensaios de epistemologia e didática. São Paulo: Escrituras, 2003.

MORAES, S. E. Habermas e a ação comunicativa na escola. In: MACHADO, N.; CUNHA, M. (orgs.) Linguagem, conhecimento, ação: ensaios de epistemologia e didática. São Paulo: Escrituras, 2003. 
NÓVOA, A. Vidas de professores. Portugal: Porto, 1995.

POLANYI, M. The Tacit dimension. Garden City, New York: Doubleday, 1967.

ROCKWELL, E.; EZPELETA, J. Pesquisa participante. São Paulo: Cortez, 1989.

ROUSSEAU, J. J. Oeurres complétes, 2. Paris: Seuil, 197I. Discours sur les sciences et les Arts.

SCHÖN, D. The Reflective practitioner: how professionals think in action. New York: Basic Books, 1983.

SANTOS, B. S. Um discurso sobre as ciências. 12.ed. Porto: Afrontamento, 2001.

TELLIS, W. Introduction to case study. The Qualitative Report, v.3, july 1997. Disponível em: http://mww.nova.edu/ssss/QR/QR3-2/tellis I .html.

VASCONCELOS, C. Disciplina: construção da disciplina consciente e interativa em sala de aula. Cadernos de Pedagogia, n.4, 1993.

WILLIS, P. Aprendendo a ser trabalhador: escola, resistência e reprodução social. Porto Alegre: Artes Médicas, 1991.

YIN, R. Case study research: design and methods. 2.ed. Beverly Hills: Sage, 1994.

Estudo de caso: planejamento e métodos. 2.ed. Porto Alegre: Bookman, 2001 .

Recebido em: março 2004

Aprovado para publicação em: maio 2006 


\section{Errata}

Na edição v.36, n. I29, set./dez.2006, à p.653, consideramos necessário precisar o vínculo institucional da autora Silvia Elizabeth Moraes, que é Pesquisadora Visitante, bolsista do Programa de Desenvolvimento Científico e Tecnológico Regional - DCR/Conselho Nacional de Pesquisas Tecnológicas - CNPq/Fundação Cearense de Apoio ao Desenvolvimento Cientíico e Tecnológico - Funcap -, na Universidade Federal do Ceará - UFC. 
O arquivo disponível sofreu correções conforme ERRATA publicada no Volume 37 Número 130 da revista. 